\title{
SEOM guidelines 2016: an update
}

\author{
A. Santaballa ${ }^{1} \cdot$ M. Martín ${ }^{2}$
}

Published online: 1 December 2016

(C) Federación de Sociedades Españolas de Oncología (FESEO) 2016

The Spanish Society of Medical Oncology (SEOM) publishes a new edition of the SEOM's Clinical Practice Guidelines.

Clinical guidelines are considered as a tool for giving the patients the best care based on the most consistent scientific evidence. Therapy based on guidelines has been shown to lead to better clinical outcomes compared with locally adapted therapeutic strategies and this would also lead to improved quality of care for the patients [1].

Recently, Salvador et al. [2] reported the results of a recent comprehensive survey conducted by SEOM. This report reveals great variability in drug access, not only between different regions but also between centers from the same region.

The purposes of SEOM guidelines are, first to be a useful tool for medical oncologists to provide the best care for their patients based on the scientific evidence care, considering the peculiarities of the Spanish healthcare system. The second one is to be a reference to claim the best treatments to health authorities and guarantee the equity of access to the best care for all patients in our country.

As in 2015 SEOM guidelines edition, SEOM and the major of Spanish Cooperative Research Groups have established an alliance to guarantee the quality of guidelines content and to collaborate in the selection of authors of the manuscripts [3].

A. Santaballa

santaballa_ana@gva.es

1 Medical Oncology Department, Hospital Universitari i Politècnic La Fe, Valencia, Spain

2 Medical Oncology Department, Hospital General Universitario Gregorio Marañón, Madrid, Spain

In this issue, 11 guidelines are published, ten of them are updated topics and is the first time that fertility guideline have been included.

Testicular cancer represents the most common malignancy in males aged 15-34 years and is considered a model of curable neoplasm. In germ cell testicular cancer guideline, authors remark the objectives in the management of these cancers, reducing treatment burden and focusing on survivorship [4].

Treatment options for the management of ovarian cancer have been also updated, including the most recent findings in biology and targeted therapies [5].

Molecular classification, diagnosis staging and the different available options of treatment are discussed in muscle-invasive and metastatic urothelial bladder cancer [6].

In localized rectal cancer guideline, authors have pointed out that localized rectal adenocarcinoma is a heterogenous disease and the importance of a preoperative multidisciplinary evaluation to recommend the best treatment option, being surgery the mainstay of treatment [7].

Pancreatic and esophageal cancers are aggressive tumors. Pancreatic cancer guideline has been updated. Authors conclude that a better knowledge of the molecular biology of this disease, focusing on personalized cancer therapies will improve the results in this tumor [8]. There are two different pathological subtypes of esophageal cancer with differences in their localization and underlying factors. Authors remark in esophageal cancer guideline, the complexity of its management and the need of a multidisciplinary approach [9].

Soft tissue sarcoma and GIST guidelines have been also updated in this issue. Soft tissue sarcomas are uncommon and heterogenous disease and a multidisciplinary approach is crucial for success. Diagnosis and available treatment 
options are discussed in the guideline [10]. Similarly, the approaches to the available options for diagnosis and treatment GIST have been updated, incorporating recent advances in molecular findings and targeted therapies [11].

SEOM are aware of counseling about fertility preservation options in young patients with curable tumors, as another tool to improve quality of life in this population. The incorporation of fertility preservation and reproduction in cancer patients: SEOM clinical practice guideline is the result of this concern. Authors discuss gonadal toxicity of cancer treatment and options to preserve fertility in males and females, breast and ovarian cancer especially concerns and options in prepuberal patients [12].

Antiemetic SEOM guideline has been update this year due to incorporate the evidences about new molecules that have improved the control of chemotherapy-induced emesis [13].

The management of bone metastases in solid tumors are discuss in a new guideline emphasizing in the multidisciplinary approach [14].

Acknowledgements Members of the executive board of the SEOM: Martin M, Vera R, Rodríguez CA, Muñoz M, Aparicio J, GarciaCampelo R, González Flores E, Lázaro M, Santaballa A, Seguí MA, Sepulveda JM, Virizuela JA. Members of the executive boards of the Spanish Cancer Research Cooperative Groups (TTD, GEMCAD, GEICO, GEIS, SOGUG, GG) and the Continuous Care SEOM Section.

\section{References}

1. Isla Casado D, González-Martín A, Alba Conejo E. The relevance of Spanish society for medical oncology (SEOM)'s clinical oncology guidelines. Clin Transl Oncol. 2010;12:707-8. doi:10.1007/s12094-010-0582-9.
2. Salvador J, Urtasun JA, Duart FJB, Garcia-Campelo R, Carbonero RG, Lianes P, et al. Clin Transl Oncol. 2016. doi:10.1007/s12094-016-1535-8.

3. Rodriguez CA, Martín M. SEOM guidelines 2015: a new era in the collaboration with the Spanish Cancer Research Cooperative Groups. Clin Transl Oncol. 2015;17:937-8

4. Aparicio J, Terrasa J, Durán I, Germà-Lluch JR, Gironés R, González-Billalabeitia E, et al. SEOM Clinical Guideline for the management of germ cell testicular cancer (2016). Clin Trans Oncol. 2016. doi:10.1007/s12094-0161566-1.

5. Santaballa A, Barretina P, Casado A, García Y, González-Martín A, Guerra E, et al. SEOM Clinical Guideline in ovarian cancer (2016). Clin Transl Oncol. 2016. doi:10.1007/s12094-016-1588-8.

6. Lázaro M, Gallardo E, Doménech M, Pinto Á, González del Alba, A, Puente J, et al. SEOM Clinical Guideline for treatment of muscle-invasive and metastatic urothelial bladder cancer (2016). Clin Transl Oncol. 2016. doi:10.1007/s12094016-1584-z.

7. González-Flores E, Losa F, Pericay C, Polo E, Roselló S, Safont MJ, et al SEOM Clinical Guideline of localized rectal cancer (2016). Clin Transl Oncol. 2016. doi:10.1007/s12094-016-1591-0.

8. Vera R, Dotor E, Feliu J, González E, Laquente B, Macarulla T, et al. SEOM Clinical Guideline for the treatment of pancreatic cancer (2016). Clin Transl Oncol. 2016. doi:10.1007/s12094-016-1586-x.

9. Martin-Richard M, Díaz Beveridge R, Arrazubi V, Alsina M, Galan Guzmán M, Custodio AB, et al. SEOM Clinical Guideline for the diagnosis and treatment of esophageal cancer (2016). Clin Transl Oncol. 2016. doi:10.1007/s12094-0161577-y.

10. López-Pousa A, Martin Broto J, Martinez Trufero J, Sevilla I, Valverde C, Alvarez R, et al. SEOM Clinical Guideline of management of soft tissue sarcoma (2016). Clin Transl Oncol. 2016. doi:10.1007/s12094-016-1574-1.

11. Poveda A, Martinez V, Serrano C, Sevilla I, Lecumberri MJ, de Beveridge RD, et al. SEOM Clinical Guideline for gastrointestinal sarcomas (GIST) (2016) Clin Trans Oncol. 2016. doi:10.1007/s12094-016-1579-9.

12. Muñoz M, Santaballa A, Seguí MA, Beato C, de la Cruz S, Espinosa J, et al. SEOM Clinical Guideline of fertility preservation and reproduction in cancer patients (2016). Clin Transl Oncol. 2016. doi:10.1007/s12094-016-1587-9.

13. De las Peñas R, Blasco A, De Castro J, Escobar Y, García-Campelo R, Gúrpide A, et al. SEOM Clinical Guideline update for the prevention of chemotherapyinduced nausea and vomiting (2016). Clin Transl Oncol. 2016. doi:10.1007/ s12094-016-1583-0.

14. Grávalos C, Rodríguez C, Sabino A, Seguí MÁ, Virizuela JA, Carmona A, et al. SEOM Clinical Guideline for bone metastases from solid tumours (2016). Clin Transl Oncol. 2016. doi:10.1007/s12094-016-1590-1. 